\title{
Experimental and Theoretical Design Methodology of Hemispherical Shells under Extreme Static Loading
}

\author{
Sh. U. Galiev, , J. Blachut, ${ }^{\text {b }}$ E. D. Skurlatov, ${ }^{\text {c }}$ O. P. Panova, ${ }^{\text {d }}$ G. Moltschaniwskyj, \\ and Z. Cui" \\ a Department of Mechanical Engineering, The University of Auckland, New Zealand \\ b Department of Engineering, The University of Liverpool, Liverpool, UK \\ ${ }^{\mathrm{c}}$ CNIIM, Korolev Institute, Moscow, Russia \\ d Pisarenko Institute of Problems of Strength, National Academy of Sciences of Ukraine, \\ Kiev, Ukraine
}

удК 539.4

\section{Экспериментально-теоретическая методология проектирования полусферических оболочек под действием экстремального статического нагружения}

Ш. У. Галиев ${ }^{a}$, Дж. Блачуг ${ }^{6}$, Е. Д. Скурлатов ${ }^{\mathrm{B}}$, О. П. Пановаг ${ }^{\mathrm{r}}$ Г. Молчанивский ${ }^{\mathrm{a}}$, 3. Цуй

а Отделение механики при Оклендском университете, Окленд, Новая Зеландия

${ }^{\circ}$ Отделение механики при Ливерпульском университете, Ливерпуль, Великобритания

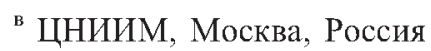

${ }^{г}$ Институт проблем прочности им. Г. С. Писаренко, НАН Украины, Киев, Украина

Представлень математические зависимости, описывающие результаты исследований металлических полусферических оболочек при статическом нагружении внешним давлениел. При этом исследовались поведение и условия потери устойчивости как пустотельх, так и заполненных пенопластом оболочек с геометрическими несовериенствами. Получены уравнения регрессии в виде неполньхх кубических полиномов. В плоскостах определяюиих параметров построень изолинии, анализ которых позволяет сделать качественные и количественные выводы о поведении оболочек в условиях нагружения внеиним давлением.

Ключевые слюва: статическое выпучивание, внешнее давление, регрессия.

Introduction. Despite extensive research and application of powerful numerical techniques to the problem of mechanical behavior of spherical shells, the knowledge on the latter is still limited. This lack of knowledge is due to two main difficulties. Firstly, in contrast to beams or plates, buckling of shells is generally sensitive to initial geometric imperfections induced during fabrication process or operation. Secondly, experimental data are available only for a limited number of cases. Indeed, in [1] it is pointed out that there is a great need for more experimental data in the area of shell buckling.

(C) Sh. U. GALIEV, J. BLACHUT, E. D. SKURLATOV, O. P. PANOVA, G. MOLTSCHANTWSKYJ, Z. CUI, 2004 
Important experimental results have been obtained during the last few years and, in principle, there are two ways in which this data could be utilized. In the first approach, experiments are used to benchmark the numerical calculations. For example, Blachut and Galletly [2] examined the load-carrying capacity of spun steel hemispheres under static external pressure. The effects of both thickness and shape imperfections on the collapse strength were discussed. Experimental and numerical results were given for seven spun hemispheres and comparisons with design codes were also provided. The ratios of the experimental to the numerical collapse pressures varied between 0.56 and 1.21 . In the second approach, the experimental data is used to construct analytical expressions which subsequently could allow the design of spherical shells without resorting to numerical methods. Gupta et al. [3], for example, studied the response of shallow spherical shells under axial compression between two rigid plates. An analytical model for the load-compression path and for the mean collapse loads was developed. The model uses the concept of stationary and rolling plastic hinges. The authors emphasized that the analytical predictions match well the experimental observations. Using this methodology, Gupta et al. [4] have also developed an analytical expression for the prediction of load-deformation and energy-compression behavior of glass/polyester composite hemispherical shells under quasi-static and dynamic axial compression.

Thus, there are some particular cases of research which may be considered very useful. However they are limited to cases with a small range of imperfections and/or to very specific loading. This is particularly true for composite shells. The classic buckling theory and numerical methods are usually unapplicable to these structures: mechanical properties of composite shells made from a variety of composite materials are often unknown. These properties strongly depend on the technology of material fabrication and, in turn, on component manufacturing route. Therefore, it is expedient to design thin-walled structures using analytical expressions derived from experiments on specimens similar to structures which are to be designed.

To this end it is possible to use different methods for construction of analytical expressions describing the available experimental data. One of possible tools here is a regression method. The method has already been used by Karmishin et al. $[5,6]$ to design thin-walled structures.

The aim of this paper is to extend the regression method to the design of empty, foam filled and geometrically imperfect shells under an external pressure.

1. Geometrical Imperfections and Investigation Techniques. It is well known that even small level of initial geometric imperfections can significantly affect the behavior of thin-walled structures. Thin-walled structures carry loads transverse to their mid-surface by a very efficient membrane action, in which the shape is the most important design factor. Whenever the shape is modified (due to imperfections produced by an external cause), then the way the equilibrium is satisfied also changes. As a result, a small modification of shell's geometry can produce a large reduction in the buckling load of the shell. But not only the buckling capacity is modified. The second important consequence is the elastic stress re-distribution that occurs. As a result, the thin-walled structure is required 
to develop bending stresses to compensate for the loss of membrane resistance to the loads.

Let us define a geometric imperfection as a permanent change in the ideal shape of a structure. This could be caused either by fabrication process or this could occur during exploitation of an existing structure. No matter how accurately one tries to construct or how carefully one exploits a thin-walled structure, there is always a possibility of imperfections' occurrence. Also, due to operational procedures one should, for example, be able to predict the strength of existing thin-walled structures which have accumulated imperfections over the time. One may need to renew and/or repair the existing structures which have developed imperfections. An urgent need to support a thin-walled component in order to eliminate the possibility of its catastrophic collapse might also arise. These are just a sample of situations which can occur in practice. Thus, there is a need to understand the behavior of thin-walled structures with imperfections, in order to be able to predict an altered load-carrying capacity envelope.

This work is focused on buckling of spherical shells. This shape is the simplest one but it is very sensitive to initial geometrical imperfections. For example, using the linear theory R. Zoelly [7] and L. S. Leibenson [8] showed that the buckling load of thin elastic spherical shell is

$$
P=2\left[3\left(1-v^{2}\right)\right]^{-0.5} E h^{2} / R^{2},
$$

where $P$ is the external pressure, $E$ is Young's modulus, $h$ is wall thickness of the shell, $v$ is Poisson's ratio, $R$ is mean radius of the spherical shell. In particular, the critical stress $\sigma_{c}$ becomes $\sigma_{c}=0.606 E h / R$ for $v=0.3$. However, experiments have shown that the true critical pressure consists of only $0.25 \%$ of the theoretical value given by Eq. (1) [9]. There are several assumptions aimed to explain discrepancies between experimental buckling loads and predictions obtained from the classic theory. For example, in [9], this discrepancy is attributed to the influence of geometrical non-linearity of a spherical shell. Later, Mushtary and Syrkin [10] corrected formula (1), and the following expression for the buckling load was proposed

$$
P=0.36\left[\left(1-v^{2}\right)\right]^{-0.5} E h^{2} / R^{2} .
$$

On the other hand, it was considered that small initial geometric imperfections were mainly responsible for these discrepancies. Indeed, it was found that thin shells having the true spherical shape have the critical loads close to the theoretical prediction according to Eq. (1) (up to $90 \%$ or more [11]).

Subsequently a large number of papers devoted to buckling of spherical shells has been published. The current paper does not intend to review them. Only some key and relevant publications are mentioned. Publications [12-14] discussed important experiments and their correlation with the classical theory. Also, 249 papers devoted to experimental investigations of behavior of spherical shells loaded by static or dynamic loads were reviewed in [15]. More recent entries can be found in [16-19]. 
1.1. The Regression Method [20, 21]. Many variables contribute to the structural response of shells subjected to loads, which cause large deformation and buckling phenomena. It is not feasible to investigate the influence of every variable. Therefore a designer usually selects dimensional groups of variables which govern the structural response. These groups are naturally represented in dimensionless analytical equation which approximates the experimental data. As it has already been mentioned, there are several methods available for derivation of such analytical equation. In particular, the relationship between the dependent variable $y$, and $i$ independent variables $x_{i}$ may be written in the form of nonlinear algebraic equation (usually in the form of a polynomial). Let us use the nonlinear multiplicative model written, for the case of $i=2$, as

$$
\begin{aligned}
y=b_{0}+ & b_{1} x_{1}+b_{2} x_{2}+b_{11} x_{1}^{2}+b_{22} x_{2}^{2}+b_{12} x_{1} x_{2}+ \\
& +b_{111} x_{1}^{3}+b_{112} x_{1}^{2} x_{2}+b_{122} x_{1} x_{2}^{2},
\end{aligned}
$$

where $b_{0}, b_{1}, b_{2}, \ldots, b_{122}$ are unknown coefficients. The nonlinear combinations of $x_{i}$ may be taken as distinct variables, i.e., as $x_{3}=x_{1}^{2}, x_{4}=x_{1} x_{2}, x_{5}=x_{2}^{2}$, $\ldots, x_{8}=x_{1} x_{2}^{2}$. In this case, results of $j$ experiments can be described by the following set of linear algebraic equations:

$$
\begin{aligned}
y^{(j)}=b_{0} & +b_{1} x_{1}^{(j)}+b_{2} x_{2}^{(j)} x_{2}+b_{11} x_{3}^{(j)}+b_{22} x_{4}^{(j)}+ \\
& +b_{12} x_{5}^{(j)}+b_{112} x_{6}^{(j)}+b_{122} x_{7}^{(j)} .
\end{aligned}
$$

If $j=8$, then it is possible to find $b_{0}, b_{1}, b_{2}, \ldots, b_{122}$ from Eqs. (4). The system of linear equations can be written as

$$
\mathbf{y}=\mathbf{X b}
$$

where $\mathbf{y}$ is a column vector of known and dimensionless values defined by experiments, $\mathbf{X}$ is a matrix of variables, and $\mathbf{b}$ is a column vector of unknown coefficients. It needs to be emphasized that each element of $\mathbf{y}$ and $\mathbf{X}$ is determined from experiments. Next, the principle of least squares is used in order to find the best approximation fit. An approximation according to this principle gives us the following expression for elements of vector $\mathbf{b}$ :

$$
\mathbf{b}=\left(\mathbf{X}^{T} \mathbf{X}\right)^{-1} \mathbf{X}^{T} \mathbf{y}
$$

where $\mathbf{X}^{T}$ is the transposed matrix and $\left(\mathbf{X}^{T} \mathbf{X}\right)^{-1}$ denotes the inverse of $\mathbf{X}^{T} \mathbf{X}$.

1.2. Application of the Regression Method to the Spherical Shell Buckling Problem. Let us use the theory of planning of experiments and the dimensional analysis to construct equation (5). It has already been mentioned that variables $x_{1}$ and $x_{2}$, in Eq. (3), are coded variables. The values of: $-1,0,1$ have 
been adopted in this paper. The coded variables are related to natural, and dimensionless variables $X_{1}$ and $X_{2}$. The latter variables are determined by shell's geometry and by loading. The coding is made according the following scheme:

$$
\begin{gathered}
x_{i}=\left(X_{i}-X_{0 i}\right) / \Delta X_{i}, \\
X_{0 i}=0.5\left(X_{i \text { max }}+X_{i \text { min }}\right), \quad \Delta X_{i}=0.5\left(X_{i \max }-X_{i \min }\right), \quad i=1,2,
\end{gathered}
$$

where $X_{i}$ is a current value of natural variable, $X_{i \max }$ and $X_{i \min }$ are the maximum and the minimum values of natural variables, $X_{0 i}$ are values of natural variables at the centre of the experimental plane, and $\Delta X_{i}$ is an interval of variation of $X_{i}$. Expressions for $X_{i}$ are determined next for several experimental cases. For each set of buckling experiments nine shell specimens were used. Every experiment/test was repeated three times and then the average values were used. A typical experimental shell specimen is sketched in Fig. 1. Details about experimental test equipment are given elswehere $[5,6,22]$.

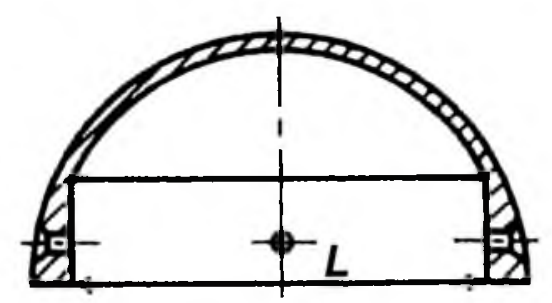

Fig. 1. Typical empty hemispherical shell used in experiments.

Let us now illustrate how values of $x_{i}$ are calculated. Assume that $50 \leq X_{1} \leq 550,0.2 \leq X_{2} \leq 1$, and the centre of experimental plane is prescribed by $X_{01}=300$, and $X_{02}=0.6$. Then, using Eq. (7) one finds $\Delta X_{1}=250, \Delta X_{2}=0.4$, $x_{1}=\left(X_{1}-300\right) / 250$, and $x_{2}=\left(X_{2}-0.6\right) / 0.4$. Thus, at the ends of the intervals one has $x_{i}=1$ or $x_{i}=-1$, and at the centre, $x_{i}=0$.

The next section provides details about experiments which form the basis for the proposed design equations given later in the paper.

2. Buckling of Empty or Supported Hemispherical Shells Having a Local Circular Dent under Static External Pressure. Hemispherical shells from titanium alloy $(E=110.0 \mathrm{GPa}$ ) were tested in order to establish a sample of their buckling characteristics. Shells were manufactured by spinning technology. Then they were welded to thick base plate containing a number of holes. The holes were used to bolt shells to motionless equipment (see Fig. 1). All shells were annealed before testing. A radius of these shells was $0.05 \mathrm{~m}$ and the wall thickness varied.

These metallic shells were either empty inside or supported by elastic media. In the ensuing experimental tests it was aimed to study the influence of the depth and of the elastic media (styrofoam) on the buckling strength of shells. The styrofoam was glued to the shell. The initial imperfections (circular dents) were localized at the pole of these shells. The dent geometry was characterized by its depth $W_{0}$ and angular dimension $\alpha$. The angle $\alpha$ is related to the dimensionless thickness ratio $h / R$ and depth $W_{0}$ as follows: 


$$
\alpha=144\left((h / R)^{0.12}\left(W_{0} / R\right)^{0.08}\right. \text {, }
$$

where $R$ is the mean radius of the perfect shell. Tested shells had different wall thickness and different stiffness of the styrofoam. Depth of the indent at the pole was formed with the help of a shock wave generated by a small shock tube - see $[5,6]$ for further details. After formation of the imperfection at the pole, the shell was loaded by external pressure using either oil or gas as working bodies. In the first case (stiff loading), shells experienced dynamic snap-buckling. In the second case (soft loading), no dynamic snap-buckling was observed. However, the magnitude of the buckling load was the same in both cases.

After the snap-buckling, the depth of the dent increased and its magnitude was comparable with $R$. Sometimes, the depth did not increase but instead small dents were formed around the initial dent as a result of buckling.

The experimental values of critical buckling stress and pressure were determined for a wide range of shells. Using these values, the regression equation was constructed. It related the critical stress with the initial dent depth $W_{0}$ and the ratio $h / R$. For supported shells we have $h / R=250$, and the regression equation relates $\sigma_{c}$ to mechanical properties of the styrofoam and the dent depth $W_{0}$.

\subsection{Buckling of Empty or Supported Hemispherical Shells.}

2.1.1. Empty Shells. In this case, $X_{1}=R / h, X_{2}=W_{0} / R$ and the experimental test data are shown in Table 1 , where $y_{*}^{\text {exp } t}=100 \sigma_{c}$. According to these data, the following regression equation was obtained

$$
\begin{gathered}
y_{*}=0.11222-0.017 x_{1}-0.0195 x_{2}+0.00466 x_{1}^{2}-0.00283 x_{2}^{2}+ \\
+0.0065 x_{1} x_{2}-0.0025 x_{1}^{2} x_{2}-0.000499 x_{1} x_{2}^{2} .
\end{gathered}
$$

Critical loads $y_{*}$ calculated according to Eq. (9), and the difference, $\Delta=\left|y_{*}-y_{*}^{\text {exp } t}\right|$, are given in Table 2. Curves $y_{*}$ are depicted in Fig. 2. Using these curves it is possible to determine critical values of the ratio $R / h$, the initial imperfection $W_{0} / R$, or the loading $P$ (since the stress $\sigma=P R^{2} / E h^{2}$ ).

2.1.2. Styrofoam-Filled Hemispherical Shells. In this case, $X_{1}=W_{0} / R$, $X_{2}=k R / E$, while $k$ characterizes the stiffening characteristic of the foam. Using the experimental data given in Table 3 the following regression equation was obtained

$$
\begin{aligned}
y_{*} & =0.43924-0.08333 x_{1}+0.20975 x_{2}-0.00416 x_{1}^{2}-0.09372 x_{2}^{2}- \\
& -0.09372 x_{2}^{2}-0.03475 x_{1} x_{2}+0.00099 x_{1}^{2} x_{2}+0.02005 x_{1} x_{2}^{2} .
\end{aligned}
$$

Critical loads $y_{*}$ calculated according to Eq. (10) and the difference, $\Delta=\left|y_{*}-y_{*}^{e x p}\right|$, are given in Table 4. Curves $y_{*}$ are shown in Fig. 3. Using 
Sh. U. Galiev, J. Blachut, E. D. Skurlatov, et al.

$\mathrm{T}$ a b 1 e 1

Dimensionless Experimental Data for Buckling of Empty Titanium Hemispheres and Values of Coded Variables $x_{1}$ and $x_{2}$

\begin{tabular}{|c|c|c|c|c|c|c|c|c|c|}
\hline Test No. & 1 & 2 & 3 & 4 & 5 & 6 & 7 & 8 & 9 \\
\hline$x_{1}$ & +1 & +1 & -1 & -1 & +1 & -1 & 0 & 0 & 0 \\
\hline$x_{2}$ & +1 & -1 & +1 & -1 & 0 & 0 & +1 & -1 & 0 \\
\hline$y_{*}^{\exp t}$ & 8.1 & 11.2 & 10.3 & 16.0 & 10.0 & 13.4 & 9.0 & 12.0 & 11.2 \\
\hline
\end{tabular}

$\mathrm{T}$ a b 1 e 2

Dimensionless Buckling Load Predicted by the Regression Model and the Resulting Errors (from Eq. (9))

\begin{tabular}{|c|c|c|c|c|c|c|c|c|c|}
\hline$y_{*}$ & 8.105 & 11.205 & 10.305 & 16.005 & 9.988 & 13.388 & 8.988 & 111.888 & 11.222 \\
\hline $1000 \Delta$ & 5 & 5 & 5 & 5 & 12 & 12 & 12 & 12 & 22 \\
\hline
\end{tabular}

$\left(x_{2}\right) 1000 W_{0} / R$

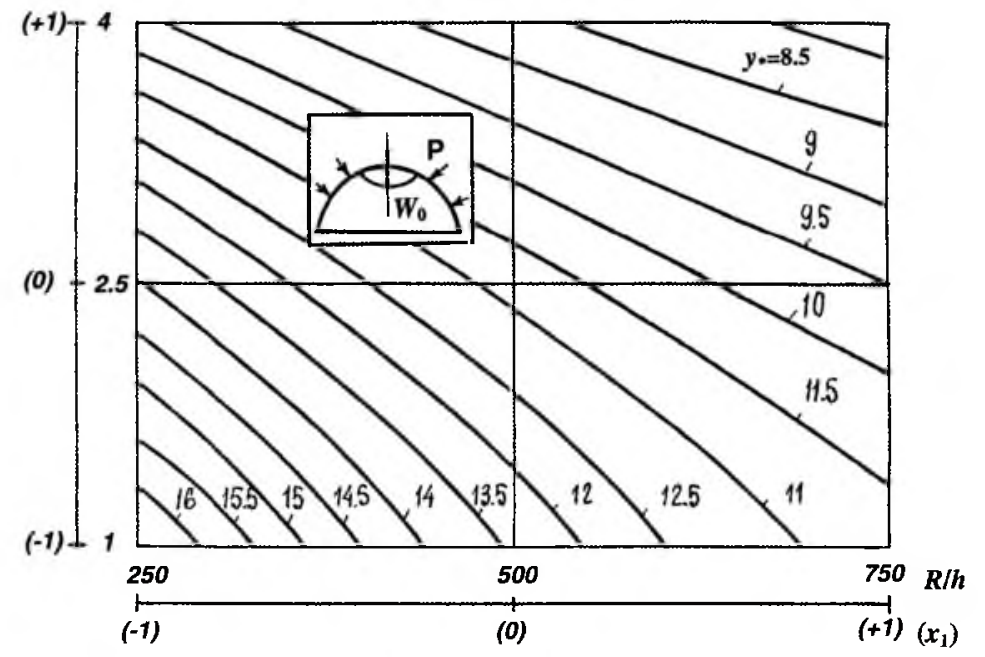

Fig. 2. Set of design curves to aid design of empty imperfect hemispheres ( $P$ is the static pressure).

these curves it is possible to determine critical values of the initial imperfection $W_{0} / R$, the loading $P$, or the foam stiffness $k$.

3. Summary and Conclusions. Buckling of the spherical shells subjected to the external pressure has been investigated with a view of producing design charts/equations. The influence of imperfections and the core material on the static buckling was considered (Figs. 2 and 3 ).

With the help of the theory of planning of experiments an influence of initial imperfections, filling (core) and loading on buckling performance of shells was analyzed. The adopted method has allowed us to derive regression equations of the form

$$
y=b_{0}+b_{1} x_{1}+b_{2} x_{2}+b_{11} x_{1}^{2}+b_{22} x_{2}^{2}+b_{12} x_{1} x_{2}+b_{112} x_{1}^{2} x_{2}+b_{122} x_{1} x_{2}^{2} .
$$


Experimental and Theoretical Design Methodology,

T a b 1 e 3

Experimental Data for Buckling of Imperfect Titanium Hemispheres Filled with Styrofoam and Values of Coded Variables $x_{1}$ and $x_{2}$

\begin{tabular}{|c|c|c|c|c|c|c|c|c|c|}
\hline Test No. & 1 & 2 & 3 & 4 & 5 & 6 & 7 & 8 & 9 \\
\hline$x_{1}$ & +1 & +1 & -1 & -1 & +1 & -1 & 0 & 0 & 0 \\
\hline$x_{2}$ & +1 & -1 & +1 & -1 & 0 & 0 & +1 & -1 & 0 \\
\hline$y_{*}^{\exp t}$ & 0.4550 & 0.1030 & 0.6519 & 0.1600 & 0.3500 & 0.5166 & 0.5535 & 0.1340 & 0.4428 \\
\hline
\end{tabular}

$\mathrm{T}$ a b 1 e 4

Dimensionless Buckling Load Predicted by the Regression Model and the Resulting Errors (from Eq. (11))

\begin{tabular}{|c|c|c|c|c|c|c|c|c|c|}
\hline y* & 0.4541 & 0.1021 & 0.6501 & 0.1591 & 0.3520 & 0.5183 & 0.5550 & 0.1357 & 0.4428 \\
\hline $1000 \Delta$ & 0.88 & 0.88 & 0.88 & 0.88 & 1.77 & 1.77 & 1.77 & 1.77 & 3.55 \\
\hline
\end{tabular}

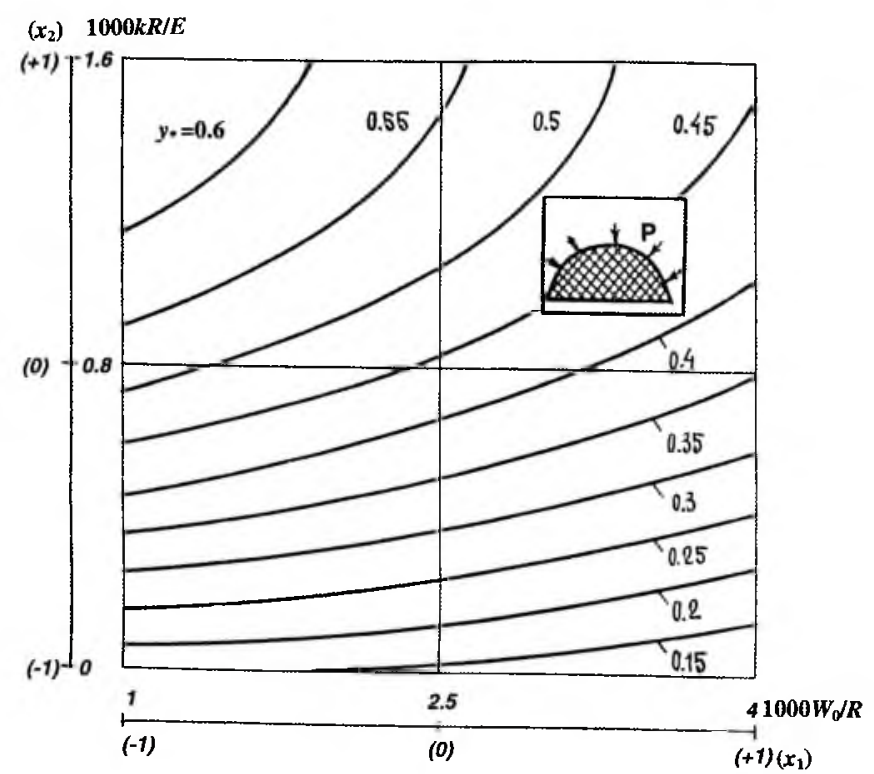

Fig. 3. Set of graphs for designing of imperfect hemispheres filled with styrofoam.

Coefficients of the nonlinear (cubic) regression equations were determined from experiments in 9 points of $x_{1}-x_{2}$ plane. It is noteworthy that every test was repeated three times and then the average values were adopted in this paper. Using the regression equations and graphs depicted in Figs. 2-3 the different hemispherical elements of structures could be designed with ease.

\section{Резюме}

Представлено математичні залежності, що описують результати досліджень металевих напівсферичних оболонок при статичному навантаженні зовнішнім тиском. При цьому досліджувалися поведінка й умови втрати стійкості 
як пустотілих, так і заповнених пенопластом оболонок із геометричною недосконалістю. Отримано рівняння регресії у вигляді неповних кубічних поліномів. У плоскостях визначальних параметрів побудовано ізолінії, аналіз яких дозволяє зробити якісні і кількісні висновки щодо поведінки оболонок в умовах навантаження зовнішнім тиском.

1. L. S. Beedle, Stability of Metal Structures: A World View, 2nd Edition, Stability Research Council, USA. (1991).

2. J. Blachut and G. D. Galletly, "Buckling strength of imperfect steel hemispheres," Thin-Walled Structures, 23, 1-20 (1995).

3. N. K. Gupta, G. L. E. Prasad, and S. K. Gupta, "Axial compression of metallic spherical shells between rigid plates," Thin-Walled Structures, 34, 21-41 (1999).

4. N. K. Gupta and G. L. E. Prasad, "Quasi-static and dynamic axial compression of glass/poliester composite hemispherical shells," Int. J. Impact Eng., 22, 757-774 (1999).

5. A. V. Karmishin, E. D. Skurlatov, V. G. Startsev, and V. A. Fel'shtein, Transient Aeroelasticity of Thin Structures [in Russian], Mashinostroenie, Moscow (1982).

6. A. V. Karmishin, A. I. Zhukov, V. G. Kolosov, et al., Methods of Dynamic Design and Tests of Thin-Walled Structures [in Russian], Mashinostroenie, Moscow (1990).

7. R. Zoelly, Promotionarbeit, Zurich, Technische Hochschule(1915).

8. L. S. Leibenson, Proceedings of Tartu University (Yurjevskij Universitet), 25, No. 5, 1-22 (1917).

9. Th. Karman and H. S. Tsien, "The buckling of spherical shells by external pressure," J. Aeronaut. Sci., 7, No. 2, 43-50 (1939).

10. X. M. Mushtary and R. G. Syrkin, "About nonlinear theory of buckling of elastic equilibrium of thin spherical shell under action of uniformly distributed normal external pressure," Appl. Math. Mech., 14, 573-586 (1950).

11. A. V. Pogorelov, Geometric Theory of Shell Stability [in Russian], Nauka, Moscow (1966).

12. R. L. Carlson, R. L. Sendelbeck, and N. J. Hoff, "Experimental studies of the buckling of complete spherical shells," Exp. Mech., 7, No. 7, 281-288 (1967).

13. N. Jones and C. S. Ahn, "Dynamic elastic and plastic buckling of complete spherical shells," Int. J. Solids Struct., 10, 1357-1374 (1974).

14. G. D. Galletly, "On the buckling of shallow spherical caps subjected to uniform external pressure," AIAA J., 14, 1331-1333 (1974).

15. E. I. Grigolyuk and V. I. Mamai, Mechanics of Deformation of Spherical Shells [in Russian], Institute of Mechanics of the Moscow State University, Moscow (1983). 
16. E. I. Grigolyuk and V. I. Shalashilin, Problems of Nonlinear Deformation [in Russian], Nauka, Moscow (1988).

17. J. Singer, J. Arbocz, and T. Weller, Buckling Experiments, Vol. 2, John Wiley \& Sons, New York (2002).

18. A. H. Guz', I. Yu. Babich, D. V. Babich, et al., Buckling of Structural Elements [in Russian], "A.C.K," Kiev (2001).

19. J. Arbocz and J. H. Starnes Jr., "Future directions and challenges in shell stability analysis," Thin-Walled Structures, 40, 729-754 (2002).

20. F. N. Kerlinger and E. J. Pedhazur, Multiple Regression in Behavioral Research, Holt, Rinehart, and Winston, New York (1973).

21. W. D. Berry and S. Feldman, Multiple Regression in Practice, Sage Publications, Beverly Hills, California (1985).

22. Sh. U. Galiev, "Experimental observations and discussion of counterintuitive behavior of plates and shallow shells subjected to blast loading," Int. J. Impact Eng., 18, 783-802 (1996). 